\title{
$\mathrm{CCTV}$ 존재 여부가 보육교사의 안전의식과 안전실천에 미치는 영향
}

\author{
권미란 ${ }^{*}$ \\ ${ }^{1}$ 나사렛대학교 아동학과
}

\section{The Effects of the Safety Awareness and Safety Practice of the Day-Care Teacher according to the Presence of CCTV}

\author{
Mee-Rhan Kwon ${ }^{1^{*}}$ \\ ${ }^{1}$ Department of Child studies, Nazarene University
}

\begin{abstract}
요 약 본 연구는 CCTV 존재 유무에 따른 보육교사의 안전의식과 안전실천 간의 관계를 실증적으로 분석하였으며, 특히 CCTV 존재 유무와 안전실천 간의 관계에서 안전의식이 매개효과를 가지는지에 대하여도 실증적 분석을 하였 다. T-검증 결과 CCTV 존재 유무에 따라 보육교사의 안전의식과 안전실천이 차이가 있음을 검증하였다. 회귀분석 결 과 보육교사의 안전의식이 안전실천에 양(+)의 관계로 유의한 것으로 검증되었다. 또한, CCTV 존재 유무가 안전의식 을 통해서 안전실천에 영향을 미치는 매개효과에 대해서도 검증되었다. 그 결과 안전의식이 CCTV 존재 유무와 안전 실천 사이의 매개변수의 역할을 수행하지 않는다는 결론을 얻었다.
\end{abstract}

\begin{abstract}
This study practically analyzed the relationships of safety awareness and safety practice of the day-care teacher according to the presence of CCTV and in particular, made a practical analysis about whether safety awareness have mediation effects in the relationship between presence of CCTV and safety practice. As a result of T-test analysis, safety awareness and safety practice of the day-care teacher according to the presence of CCTV is different that has been verified. As a result of regression analysis, safety awareness were positively related to safety practice. That is to say, even the mediation effects that the presence of CCTV through safety awareness related to safety practice were verified. As a result, it was concluded that safety awareness factors didn't play mediator roles between presence of CCTV and safety practice.
\end{abstract}

Key Words : CCTV, Safety awareness, Safety practice

\section{1. 서론}

현대사회의 산업화, 도시화에 따른 여성의 사회참여 증가 및 가족구조의 핵가족화가 급증하면서 보육수요가 급증하였다. 과거에는 영유아들을 사고의 위험으로부터 안전하게 보호하는 것이 주로 부모의 책임이고 의무로 인식되었으나, 현대 사회는 가족구조의 변화와 여성의 사 회 진출의 증가 등으로 인해 영유아가 부모가 아닌 다른 사람에 의해 또는 집단적으로 생활하는 형태로 변화하였다.

영유아기는 심신의 급속한 성장과 발달이 이루어지는
시기이다. 그러나 유아기는 신체적, 정신적으로 미성숙한 상태이며, 질병 및 안전사고의 발생률이 높은 시기이기도 하다.[2]

영유아 시기의 사고는 치명적인 결과를 초래하기 쉽기 때문에 특히 영유아를 안전하게 보살피는 것은 부모나 유아를 보육하는 사람들의 일차적인 책임으로 인식되고 있다.

핵가족화와 여성의 사회 진출 확대로 가정에서 아동이 보육되기 어려운 현실 속에서 보육시설은 다수의 영유아 를 보호하는 책임을 지고 있다. 그래서 보육시설을 안전

본 논문은 2011년도 나사렛대학교 학술연구비 지원에 의해서 연구되었음.

*교신저자 : 권미란(mrkwon@kornu.ac.kr)

접수일 12년 01월 27일 수정일 12년 02월 09일 게재확정일 12년 02월 10일 
한 환경으로 구성하는 일은 영유아를 책임지고 있는 보 육시설 종사자들에게 매우 중요한 관심사이다.[8] 그 동 안의 보육은 주로 양적 성장에 치중한 나머지 질적 서비 스 개선 문제에 대한 충분한 고려가 부족하였다. 그로 인 해 시설적인 면에서는 발전하였으나 질적인 요소의 하나 인 보육교사의 안전인식이나 안전실천 부분에 대해서는 소홀하였다. 따라서 보육교사의 안전인식 부족과 안전실 천 문제로 인해 많은 영유아들이 다치거나 목숨을 잃고 있는 것이 지금의 현실이다. 통계청이 밝힌 영유아의 사 망원인에 의하면, 제 1 원인은 안전사고이다.[3]

최근에는 CCTV (Closed Circuit Television: 폐쇄회로 텔레비젼)를 보육현장에 접목시켜 화상정보(교사와 아이 들의 활동모습)를 전송받을 수 있게 되었다. 가끔씩 유아 교육기관에서 발생하는 안전사고와 아이들에 대한 교사 의 심한 체벌 등의 영유아 학대사고를 의식해 부모들에 게 신뢰감을 주며 불안감을 해소시키기 위해 CCTV를 설 치하곤 한다.

보육시설에 자녀를 맡기는 부모의 입장에서는 보육기 관이 안전을 보장할 수 있는 각종 환경을 구성하고 이를 확인할 수 있는 환경이 된다면 부모들은 안심하고 생업 에 종사할 수 있을 것이다. 이러한 이유로 CCTV의 설치 는 부모들에게 안심할 수 있는 또 하나의 환경적 요소라 고 판단된다.

기존의 연구에서는 대부분 안전교육과 안전의식과의 관계를 중심으로 연구해 왔으며 안전실천에 대한 연구는 부족한 현실이다.

본 연구에서는 CCTV 존재 여부에 따라 보육교사의 안전의식과 안전실천에 어떠한 차이가 있는가를 살펴보 고자 한다. 또한 추가적으로 안전의식이 CCTV 존재 여 부와 안전실천 간의 관계에서 매개효과가 있는지 살펴보 고자 한다.

\section{2. 관련연구}

본 연구는 보육교사의 안전의식과 안전실천 간의 관계 와 CCTV 존재 여부에 따른 차이점을 살펴보기 위해 선 행 연구를 살펴본 결과, 안전교육, 안전의식에 관한 연구 는 지속적으로 이루어졌으나 CCTV와 관련하여 연구된 것은 없는 것으로 나타났다.

범죄 예방 및 억제, 심리적 안정감 향상 등의 목적으로 널리 상용되고 있는 CCTV는 폐쇄회로 텔레비전(closed circuit television)이라는 특수한 수신자에게만 서비스하 는 것을 목적으로 하는 텔레비전 전송시스템을 가리키는 화상통신용어이다.[6]
노호래(2005)는 개인의 정보인권을 보호하고 CCTV의 활용법규를 마련하여 시민의 동의와 지방정부의 협력을 통한 $\mathrm{CCTV}$ 를 설치해야 한다고 제시하였다.[4]

이주락(2008)의 연구에서는 방범용 CCTV는 일정한 수준의 범죄 예방효과를 가지는 것으로 나타났으나 범죄 전이효과도 발생하였다.[7]

안전의식이란 안전(위험하거나 사고가 날 염려가 없는 상태)에 대해 늘 관심 가지면서 위험 가능한 자극들을 감 각신경으로 받아들여 문제의식을 갖고 적극적으로 대처 하는 자세를 말한다.

유아의 안전사고는 가정, 유아교육기관, 그 외 유아들 이 생활하는 어떤 곳에서나 발생할 수 있으며 특히 부모 나 교사가 안전사고 관련 철저한 사전 대비를 하지 않았 거나 안전점검 미비, 안전지도 소홀 등 어른들의 부주의 로 인해 발생할 가능성이 높다. 안전사고를 예방하기 위 해서는 유아의 연령, 신체크기, 능력을 고려한 적절한 시 설과 설비를 완비하고, 우발사고에 대한 인식을 가지고 수시로 안전 상태를 점검하며, 유아로 하여금 스스로 안 전의식을 지닐 수 있도록 철저한 안전교육을 시키는 것 이 중요하다.

정미라(1993)는 보육교사는 교육에 관한 것 뿐 아니라 영유아들의 위생, 영양, 안전 등의 관리에 대한 내용까지 도 알아야 하며 교사양성 교육과정에 포함되어야 한다고 주장하였다.[9]

정인자(1998)는 보육시설에서 발생하는 안전사고의 실태조사에서 사고 발생영역은 실내가 많았으며, 실외 놀 이기구에서도 많은 사고가 발생하였다고 보고하였다.[10]

Robertson(1998)은 보육교사는 안전한 행동을 보이는 역할모델링, 부모와 유아에게 안전을 교육하는 교육자, 유아의 행동을 관찰하는 관찰자, 안전을 증진시키기 위한 감독자의 역할을 수행해야 한다고 주장하고 있다.[12]

윤선화(2000)는 보육교사들은 안전지식이 높을수록 안전에 대한 실천을 잘 한다고 밝히고, 유아 교사들에게 안전지식을 습득할 수 있는 안전교육 경험의 중요성을 강조하였다.[5]

김영해(2001)은 불안전한 조건과 불안전한 행위를 통 제하기 위해서 사전에 안전 지식을 부여해 줌으로써 불 안전한 조건을 배제하도록 교육하고, 불안전한 행위가 발 생하지 않도록 어려서부터 체계적인 안전교육이 필요하 다고 주장하였다.[1]

선행연구를 통해 살펴본 결과는 교육을 통해 안전의식 을 높이고 안전의식을 높임으로써 사고를 예방할 수 있 다는 주장들이 대부분이다. 또한 안전의식이 높아지면 안 전실천도 높아질 것이라고 주장하고 있다. 


\section{3. 연구모형}

본 연구에서 앞에서 제시한 $\mathrm{CCTV}$, 안전의식, 안전실 천 등 다수의 선행연구들을 토대로 연구모형을 개발하였 다. 연구모형은 그림 1 과 같다.

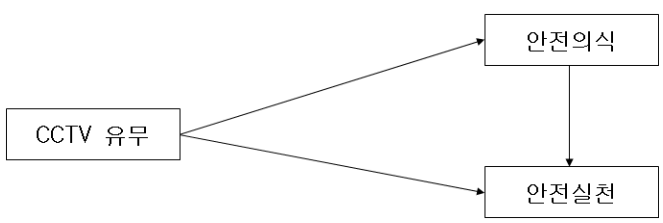

[그림 1] 연구 모형

[Fig. 1] Research Model

선행연구들과 연구모형을 바탕으로 표 1 과 같은 연구 가설을 도출하였다.

[표 1] 연구가설

[Table 1] Research Hypothesis

\begin{tabular}{|c|l|}
\hline 가설 & \multicolumn{1}{|c|}{ 가설내용 } \\
\hline 가설 1 & $\begin{array}{l}\text { CCTV의 존재 유무에 따라 보육교사의 안전의식 } \\
\text { 에 차이가 있을 것이다. }\end{array}$ \\
\hline 가설 2 & $\begin{array}{l}\text { CCTV의 존재 유무에 따라 보육교사의 안전실천 } \\
\text { 에 차이가 있을 것이다. }\end{array}$ \\
\hline 가설 3 & $\begin{array}{l}\text { 보육교사의 안전의식은 안전실천에 유의한 영향 } \\
\text { 을 미칠 것이다. }\end{array}$ \\
\hline 가설 4 & $\begin{array}{l}\text { CCTV의 존재 유무는 안전의식을 통해 안전실천 } \\
\text { 에 유의한 영향을 미칠 것이다. }\end{array}$ \\
\hline
\end{tabular}

\section{4. 실증분석}

어린이 보육기관을 직접 방문하여 설문조사를 통해 총 306 부를 수집하였으나 누락이 존재하거나 이중기재 등과 불성실한 응답자를 제외하고 총 203 부의 데이터를 가지 고 연구가설을 검증하였다.

본 연구의 응답자에 대한 빈도분석을 통해 인구통계학 적 분석을 수행하였다. 그 결과는 다음 표 2 와 같다.

[표 2] 표본의 특성

[Table 2] Properties of Sample

\begin{tabular}{|c|c|c|c|}
\hline \multicolumn{2}{|c|}{ 구분 } & 빈도(명) & 비율(\%) \\
\hline \multirow{5}{*}{ 경력 } & 3년 이하 & 82 & 40.4 \\
\hline & 4 - 6년 & 60 & 29.6 \\
\hline & 7 - 10년 & 40 & 19.7 \\
\hline & 11 - 15년 & 17 & 8.4 \\
\hline & 16년 이상 & 4 & 2.0 \\
\hline
\end{tabular}

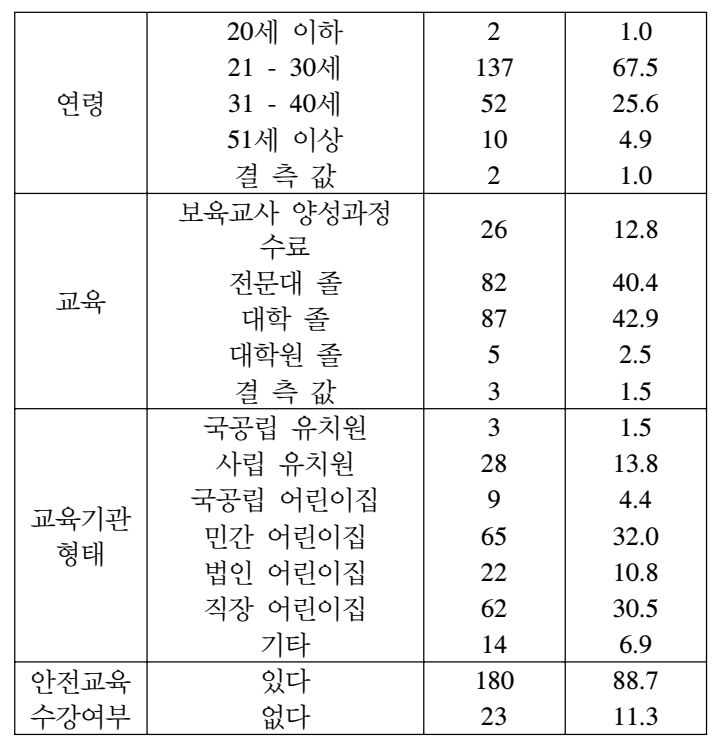

측정 변수들에 대한 타당성을 검증하기 위해 변수들에 대한 요인분석을 실시하였다. 이 요인 분석을 통해 부적 절한 항목들이 일차적으로 제거되었다. 요인 추출방법으 로는 주성분 분석(principal component analysis)을 실시하 였다. 본 연구 모형에서 제시한 것과 같이 독립변수인 $\mathrm{CCTV}$ 는 명목척도이므로 타당성 검증을 실시하지 않았 으며, 종속변수인 안전의식과 안전실천에 대하여 요인분 석을 실시하였다. 또한 요인분석을 통해 추출된 요인에 대한 신뢰성 검증을 위해 Cronbach's $\alpha$ 를 측정하였다. 종속변수에 대한 각 요인별 적재량이 0.5 이상인 변수들 만 추출하였으며, 그 중에 다른 요인에 대한 적재량의 차 이가 뚜렷하지 못한 요인은 제거하였다. 신뢰성 검증을 위해서 Cronbach's $\alpha$ 를 측정한 결과 모두 0.9 이상으로 나타나 신뢰성이 매우 높은 것으로 나타났다.

$\mathrm{CCTV}$ 존재 여부에 따라 보육교사의 안전의식에 차이 가 있는지 알아보기 위해 T-검정을 실시하였다. T-검정의 결과를 보면 CCTV 존재여부에 따라 보육교사의 안전의 식에 차이가 있는 것으로 나타났다. 따라서 가설 1이 채 택되었다. 즉 CCTV의 존재 유무에 따라 보육교사의 안 전의식에 차이가 있다고 할 수 있다. 등분산에 대한 검정 을 통해 등분산이라는 귀무가설을 기각함으로 등분산이 가정되지 않음으로 $\mathrm{T}$-검정을 하면 $90 \%$ 신뢰구간에서 $\mathrm{CCTV}$ 유무에 따라 안전의식이 차이가 있음을 알 수 있 다. 그 결과는 표 3 에 제시하였다. 
[표 3] CCTV와 안전의식에 대한 T-검정

[Table 3] T-Test of CCTV and Safety Awareness

\begin{tabular}{|c|c|c|c|c|}
\hline 안전의식 & $\begin{array}{c}\text { 등분산 } \\
\text { 검정( } \mathrm{F})\end{array}$ & $\begin{array}{c}\mathrm{F} \text { 의 } \mathrm{sig} \\
\text { (유의확률) }\end{array}$ & $\begin{array}{c}\mathrm{t} \\
\text { (통계량) }\end{array}$ & $\begin{array}{c}\mathrm{t} \text { (의 } \mathrm{sig} \\
\text { (유의확률) }\end{array}$ \\
\hline 등분산이 가정됨 & 9.273 & 0.003 & 1.769 & 0.078 \\
등분산이 가정되지 않음 & & & 1.813 & 0.071 \\
\hline
\end{tabular}

CCTV 존재 여부에 따라 보육교사의 안전실천에 차이 가 있는지 알아보기 위해 T-검정을 실시하였다. T-검정 결과를 보면 $\mathrm{CCTV}$ 존재여부에 따라 보육교사의 안전실 천에 차이가 있는 것으로 나타났다. 따라서 가설 2가 채 택되었다. 즉 $\mathrm{CCTV}$ 의 존재 유무에 따라 보육교사의 안 전실천에 차이가 있다고 할 수 있다. 안전실천은 $99 \%$ 신 뢰구간에서 그 유의한 차이를 보이는 것으로 나타났으며, 이는 안전의식에 대한 $90 \%$ 신뢰구간 보다 높은 값이며, 이는 CCTV의 존재 유무에 따라 안전의식과 안전실천 모 두에 차이가 나타나지만 특히 안전실천에 더 많은 차이 를 보이는 것으로 나타났다. 결과는 표 4 에 제시하였다.

[표 4] CCTV와 안전실천에 대한 T-검정 [Table 4] T-Test of CCTV and Safety Practices

\begin{tabular}{|c|c|c|c|c|}
\hline 안전의식 & $\begin{array}{c}\text { 등분산 } \\
\text { 검정(F) }\end{array}$ & $\begin{array}{c}\mathrm{F} \text { 의 } \mathrm{sig} \\
\text { (유의확률) }\end{array}$ & $\begin{array}{c}\mathrm{t} \\
\text { (통계량) }\end{array}$ & $\begin{array}{c}\mathrm{t} \text { 의 } \mathrm{sig} \\
\text { (유의확률) }\end{array}$ \\
\hline $\begin{array}{c}\text { 등분산이 가정됨 } \\
\text { 등분산이 가정되지 } \\
\text { 않음 }\end{array}$ & 29.725 & 0.000 & 2.752 & 0.006 \\
\hline
\end{tabular}

보육교사의 안전의식이 보육교사의 안전실천에 영향 을 미치는지를 알아보기 위해 단순회귀분석을 실시했다. 단순회귀분석 결과를 보면 안전의식이 안전실천에 유의 한 영향을 미치는 것으로 나타났다. 따라서 가설 3 이 채 택되었다. 즉 보육교사의 안전의식은 안전실천에 유의한 영향을 미친다고 할 수 있다. Beta 값이 1.019로 나타나 안전의식이 높을수록 안전실천이 높아지는 것을 알 수 있으며 그 증가폭이 거의 동일하다는 결과를 얻었다. 회 귀모형에 대한 예측력은 $41.6 \%$ 로 높은 설명력을 보여주 고 있다. 그 결과는 표 5 에 제시하였다.

[표 5] 안전의식와 안전실천간의 회귀분석

[Table 5] Regression of Safety Awareness and Safety Practices

\begin{tabular}{|c|c|c|c|c|}
\hline 종속변수 & Beta & $\mathrm{t}$ & $\mathrm{sig}$ & adjusted $\mathrm{R}^{2}:$ \\
\hline 안전실천 & 1.019 & 11.962 & 0.000 & $\begin{array}{c}\mathrm{R}^{2}: 0.416 \\
\text { Adj. } \mathrm{R}^{2}: 0.413\end{array}$ \\
\hline
\end{tabular}

매개 효과를 검증하기 위하여 Baron and Kenny(1986)[11] 의 연구에 기초하여 보육교사의 안전의식에 대한 매개효 과를 분석하기 위하여 매개회귀분석을 실시하였다. 매개 효과에 대한 검증 결과를 보면 독립변수와 종속변수에 대한 회귀식의 회귀계수가 독립, 매개변수와 종속변수에 대한 회귀식의 회귀계수보다 작으므로 매개효과가 없음 을 나타내고 있다. 따라서 CCTV 존재 유무는 보육교사 의 안전의식에 의해 매개되어 안전실천에 영향을 미치지 않는다는 결론을 얻었다. 따라서 가설 4 는 기각되었다. 그 결과는 다음의 표 6 과 같다.

[표 6] 안전의식의 매개 효과 회귀분석

[Table 6] Intermediate Effects Regression of Safety Awareness

\begin{tabular}{|c|c|c|c|c|c|c|c|}
\hline \multirow[t]{2}{*}{ 변수 } & \multicolumn{2}{|c|}{ 독립 $\rightarrow$ 매개 } & \multicolumn{2}{|c|}{ 독립 $\rightarrow$ 종속 } & \multicolumn{2}{|l|}{$\begin{array}{l}\text { 독립 } \\
\text { 매개 }\end{array}$} & \multirow{2}{*}{$\begin{array}{l}\text { 매개 } \\
\text { 효과 }\end{array}$} \\
\hline & beta & $\mathrm{t}$ & beta & $\mathrm{t}$ & beta & $\mathrm{t}$ & \\
\hline \multirow{2}{*}{$\begin{array}{l}\text { 가족 } \\
\text { 형태 }\end{array}$} & \multirow{2}{*}{$-0.064 *$} & \multirow{2}{*}{-1.769} & \multirow{2}{*}{$-0.156 * * *$} & \multirow{2}{*}{--2.752} & $-0.092 * *$ & -2.087 & \\
\hline & & & & & $0.997 * * *$ & 11.710 & \\
\hline
\end{tabular}

\section{5. 결론}

본 연구는 CCTV 존재 유무에 따른 보육교사의 안전 의식과 안전실천 간의 관계를 실증적으로 분석하였으며, 특히 CCTV 존재 유무와 안전실천 간의 관계에서 안전의 식이 매개효과를 가지는지에 대하여도 실증적 분석을 하 였다.

어린이 보육기관을 직접 방문하여 설문조사를 통해 총 306 부를 수집하였으나 누락이 존재하거나 이중기재 등과 같은 불성실한 응답자를 제외하고 총 203 부의 데이터를 가지고 연구가설을 검증하였다.

$\mathrm{T}$-검정 결과 $\mathrm{CCTV}$ 존재 유무에 따라 보육교사의 안 전의식과 안전실천에 차이가 있다는 것을 검증하였다. 특 히 안전의식 보다는 안전실천에 차이가 극명하게 나타났 다고 할 수 있다. 안전의식과 안전실천 간의 관계를 알아 보기 위해 회귀분석을 한 결과 안전의식에 따른 안전실 천은 양 $(+)$ 의 관계로 유의한 것으로 검증되었다. 즉, 보육 교사의 안전의식이 높을수록 안전실천이 높은 것을 의미 한다. 또한 회귀모형에 대한 예측력이 $41.6 \%$ 로 높게 나 타났으며, Beta 값이 1.019로 나타나 두 변수의 변화가 거의 동일한 정도로 변경되는 것을 알 수 있다. CCTV 존 재 유무가 안전의식을 통해서 안전실천에 영향을 미치는 매개효과에 대해서도 검증되었다. 그 결과 안전의식이 CCTV 존재 유무와 안전실천 사이의 매개변수의 역할을 수행하지 않는다는 결론을 얻었다. 본 연구의 한계점으로 
는 첫째, 모집단에 대한 표본에 있어 CCTV를 설치한 보 육기관이 설치하지 않은 보육기관에 비해 현저하게 적어 충분한 표본을 확보하지 못한 점으로 인해 모집단에 대 한 대표성에 있어 문제점을 가지고 있다. 둘째, $\mathrm{CCTV}$ 를 설치한 보육기관의 수가 적은 관계로 인해 설치 장소에 따른 구분을 하지 않고 일괄적으로 설치 여부만을 기준 삼아서 연구의 목적에 적합한 데이터가 아닌 경우가 포 함될 수 있다는 한계점을 가진다.

\section{References}

[1] Yung-Hai Kim, "A study on safety consciousness and safety behavior middle school students and their parents" Inha University Graduate School, 2001

[2] Ju-Young Kim, "A study of the Status of Safety Environments of Child-care Centers and Early Childhood Teachers' Recognition of Safety according to Child-care Accreditation Participation," Woosuk University, 2009

[3] Hae-Myo No, "Relation between Safety Practice of Kindergarten Teacher and Safety Problem Solving Thought of Young Children," Won-Kwang University Graduate School, 2004

[4] Ho-Rae Roh, "Closed Circuit Television Application for Crime Prevention," Dept. of Police Administration, Semyung University, 2005

[5] Sun-hwa Yoon, “Korean early childhood teachers' safety knowledge, perception, and practice," Sookmyung Woman's University, 2000

[6] Seung Chal Lee, "Effects of Perception of CCTV and Local Environmental Factors on Fear of Crime," Dongguk University Graduate School

[7] Ju Lak Lee, "Assessing the Impact of Open-street CCTVs in Cheonan and Asan Areas," Modern society and administration, Vol.18 No.2, KAGS, 2008

[8] Hee-jeong Lee, "Investigation of the Demand of Caregivers and Parents on Children's Safety in Day Care Center," Sookmyung Woman's University Graduate School of education, 1997

[9] Mi-Ra Chung, "Issues and Future Directions of Early Childhood Education Teachers," The Korea Association of Child Care and Education 1st Conference Presentation

[10] In-Ja Jung, "A Study on the Actual Conditions of Accidents and on," Sookmyung Woman's University Graduate School of education, 1997

[11] Baron, R. M. and Kenny, D, "The moderator-mediator variable distinction in social psychological research,"
Journal of Personality and Psychology, Vol. 51,.1986

[12] Robertson, C. "Safety nutrition, and health in early education," Delmar Publishers, 1998

\section{권 미 란(Mee-Rhan Kwon)}

[정회원]

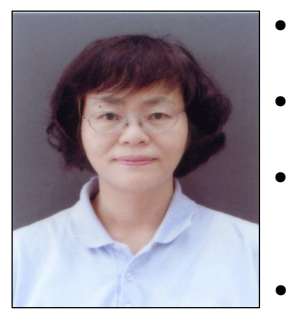

- 1980년 2월 : 수도여자사범대학 영어영문학과 졸업

- 1982년 2월 : 세종대학교 대학원 교육학과 졸업(교육학 석사)

- 1996년 5월 : 미국 Southern Nazarene University 대학원 졸 업. 유아교육학 전공(문학 석사)

- 1997년 7월 : Kansas State University 대학원 유아교육학과 1 년간 수료

- 1991년 8월 : 세종대학교 대학원 교육학 전공 박사과 정 수료

- 2009년 2월 : 한세대학교 IT학부 (공학박사)

- 1990년 3월 현재 : 나사렛대학교 아동학과 교수

<관심분야>

아동발달, 유아음악, 아동 및 청소년의 인터넷 중독 